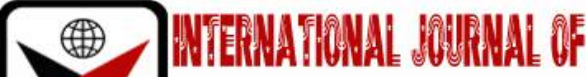

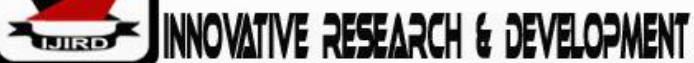

ISSN 2278-0211 (Online)

\section{The Effectiveness of Synthetic Phonics in Developing Reading Fluency among Year 2 Intermediate Pupils}

\author{
Sim Ching Loong \\ Master's Student, Universiti Kebangsaan Malaysia, Malaysia \\ Dr. Azlina Abdul Aziz \\ Senior Lecturer, Universiti Kebangsaan Malaysia, Malaysia
}

\begin{abstract}
:
Reading skill is an essential skill that is taught in every language subject in schools. Its importance is irrefutable as it relates closely to the pupils' academic and future success. Today, many Malaysian pupils are still struggling hard to read with fluency and understanding. It is noticed that educators in schools have been giving limited attention on reading fluency since reading comprehension is the ultimate goal in reading development. Researches show that mastery of reading fluency is required for comprehension to take place subsequently. Therefore, this action research aims to examine the effectiveness of synthetic phonics in developing the reading fluency of the Year 2 intermediate pupils in a sub-urban school in Dalat, Sarawak and their perception towards the intervention. Six pupils were involved in this research. Data were collected through pre-post-tests, classroom observation and structured interviews. Paired T-tests were conducted to determine the significant difference between pre-test and post-test scores of oRF assessments which were analysed in mean, standard deviation and p-value whereas classroom observation and structured interviews were analysed through content analysis. The findings indicated that pupils had improved in their reading fluency after the intervention and had positive perceptions towards the intervention. For further research, more sampling is recommended to generalise the findings.
\end{abstract}

Keywords: Reading skill, reading fluency, synthetic phonics, intermediate pupils, Year 2

\section{Introduction}

\subsection{Background of the Study}

In any language learning, it is widely known that four basic skills will be taught to the learners which are listening, speaking, reading and writing skill. Each skill has its vital role in building up a learner's complete mastery of a particular language. In Malaysia, our Ministry of Education (MoE) has never failed to concern about the English language proficiency of the pupils in schools. This is due to the powerful impact of English language. As the global language, English has been dominating most of the fields as well as in the global job market (Renukadevi, 2013). The recent announcement of Malaysia's PISA (Programme for International Student Assessment) result in 2018 indicates that there are still a lot to do in improving the reading proficiency level of our pupils. As indicated in the PISA 2018 Results Report by Organisation for Economic Cooperation and Development (OECD, 2019), our country had scored 415 in the reading domain which falls below the global average of 487.

In order to tackle the reading problems encountered by the pupils, our MoE has taken the initiative to revise the English language curriculum to align with the Common European Framework of References (CEFR) in 2017. It is then implemented in stages in all public schools in Malaysia including preschools starting from 2018. The component of phonics is still integrated in the curriculum due to the crucial role of phonics as one of the foundational reading skills to be acquired in becoming a successful reader (Tankersley, 2005; National Reading Panel, 2000; Christo \& Davis, 2008). As stated in the National Reading Panel (NRP) report published by National Institute of Child Health and Human Development (NICHD, 2000), reading skill comprises five components, namely phonological awareness, vocabulary, attitude or motivation, reading fluency and comprehension. Among these components, it is not uncommon that reading comprehension is given more emphasis in schools because it is the main goal in reading development. However, researchers discovered that pupils' lack in reading fluency is one of main reasons that results in their poor comprehension skill in reading (Adams, 1990; Kuhn, Schwanenflugal \& Meisinger, 2010; Guerin \& Murphy, 2015). Hence, this research aimed to explore on the use of synthetic phonics in building up the pupils' fluency in reading.

\subsection{Problem Statement}

As far as we are concerned, learning to read is not a simple task because it involves "complex cognitive process" of decoding a series of codes to construct meaning (Kim \& Goetz, 1995). This is supported by Jolliffe and Waugh (2017) who 
claimed that "English has a complex alphabetic code as there are 26 letters and yet approximately 44 sounds". As mentioned above, reading skill consists of five components with reading comprehension as the key goal in reading development. This is because reading without understanding is not the real purpose of reading. This has led to the lack of concern over reading fluency acquisition among the pupils in schools. This is evident when assessment on reading fluency is neither included in the classroom-based assessment nor the learning standards in the English language curriculum in Malaysia (MoE, 2018).

Despite the importance of achieving reading comprehension skill, there are studies which found out that pupils' ability in reading comprehension is influenced by their ability in reading fluency (Chard, Vaughn \& Tyler, 2002; LaBerge \& Samuels, 1974; Rasinski, 2016; Rasinski \& Nageldinger, 2016). Findings indicated that pupils with poor comprehension skill are having difficulties to read fluently. They tend to spend a lot of time to read words aloud smoothly which results in their staccato reading (Callella, 2003). When dysfluency occurs, it will certainly affect the pupils' comprehension because a great deal of cognitive energy will be used for word decoding (Wolf, Miller \& Donnelly, 2000; Ehri, 2005; Philips \& Torgensen, 2006; Rasinski \& Hoffman, 2006).

In this context, there are some local studies which had explored on this area and concluded synthetic phonics to be effective in solving dysfluency among pupils (Ding, 2015; Gomez, 2016; Lehner, 2017; Day, 2017). However, these studies do not examine reading fluency in comprehensive way. As stated in the National Reading Panel report (NICHD, 2000), reading fluency comprises three components that are accuracy, rate and prosody. Therefore, the researcher aimed to examine the effectiveness of synthetic phonics on all three components of reading fluency to provide a more comprehensive research. Six intermediate Year 2 pupils were selected to take part in this research as they were noticed to be unable to read a passage with fluency. Moreover, they had poor decoding skill which contributed to their dysfluency in reading. Thus, this research would explore on the effectiveness of synthetic phonics as the foundation in the development of reading fluency and pupils' perception towards it.

\section{Literature Review}

\subsection{Phonics Approach in the Teaching of Reading}

Reading is the gateway that opens abundant opportunities to gain success in future. As stated by International Literacy Association (2018), "Reading can be an effortless pleasure and life-changing gift" if pupils acquire the skill properly. In the teaching of reading skill, the use of phonics approach in teaching reading skill is not a recent trend too. Since nineteenth century, phonics instruction in the teaching of reading had emerged followed by numerous researches which had discovered its effectiveness in teaching pupils to read until today (Chall, 1967; NICHD, 2000; Stahl, 2001; Tallal, 2012; Prasad, Nooreiny \& Hamidah, 2016). Through phonics approach, pupils will be exposed to the letter-sound correspondence whereby they learn the relationship between letters and sounds. Their phonemic awareness will be triggered as well which refers to their "ability to hear and manipulate the individual sounds within words" (NRP, 2000). Apart from that, the knowledge of blending and segmenting phonemes will be learnt by the pupils too so that they can decode words easily.

While phonic approach is adopted by many schools worldwide, the debates on the most effective phonics instruction remain on-going (Khairul, Norlidah \& Roselina, 2014). In general, synthetic and analytic phonics are two commonly used instructions in the teaching of reading. Synthetic phonics is more to parts-to-whole approach in which pupils are exposed to identifying phonemes before blending them to read the words. Contrastingly, analytic phonics adopts whole-to-parts approach whereby pupils will learn to read the whole word first before breaking down into the smallest unit of sound which is phoneme (Shearer, Carr \& Vogt, 2019). Despite the differences between both instructions, it is noticed that synthetic phonics is gaining higher popularity and recognition compared to analytic phonics in teaching reading to children due to its huge impact in pupils' reading ability (Wyse \& Goswami, 2008; NICHD, 2000; Ehri et al., 2001).

In Malaysia, synthetic phonics is embedded in our curriculum after our Standard-based Primary School Curriculum (KSSR) is revised in 2017. English language curriculum is later aligned with CEFR for benchmarking purpose. Hence, it can be said that synthetic phonics is not a new thing in our education system and pupils are being exposed to it since preschool starting from 2017. Therefore, synthetic phonics was the phonics instruction to be examined in this research since it has been practised in schools in recent years. As indicated in the NRP report (2000), phonics instruction is best to be imparted to the pupils in early grades. This is because reading tasks get more difficult as they proceed to a higher grade or level. Failing to master phonetic knowledge in early grades may result in reading difficulties (Wagner \& Torgesen, 1987; Adams, 1990; McCandliss et al., 2003; Kuhn, Schwanenflugal \& Meisinge, 2010; Stockard \& Engelmann, 2010; Denton \& Otaiba, 2011), being left behind from other peers (Chall, Jacobs \& Baldwin, 1990; Dudley \& Mather, 2005) and school dropouts (Lehner, 2017; Denton \& Otaiba, 2011). Thus, building a strong foundational skill of phonics is truly important especially for the young learners to better prepare them in acquiring more complex sub-skills in reading. This is in line with Pokharel's (2018) statement that "acquiring literacy becomes more difficult as students grow older".

\subsection{Synthetic Phonics in the Teaching of Reading Fluency}

In the field of education especially in the aspect of language learning, reading fluency is gaining less attention and emphasis in comparison with other components of reading skill. Wolf and Katzir-Cohen (2001) had described the history of reading fluency research as "intellectually spasmodic" in which there is period of great interest followed by the gradual decline in interest. Reading fluency was perceived as "the most neglected reading skill" (Allington, 1983) until the disclosure of NRP report in 2000. As stated in the report (NICHD, 2000), reading fluency is an essential component of 
reading skill. It has been said that a pupil's future reading success can be predicted through their performance in reading fluency (Hosp, Hosp \& Howell, 2007) because reading fluency is the main bridge that links phonics to reading comprehension (Rasinski, 2004).

With the growing interest over the topic of reading fluency, the definition given to reading fluency varies over the years. Previously, reading fluency is commonly defined as accurate reading at appropriate rate without taking account into the prosody component (Hasbrouck \& Tindal, 1992; Meyers \& Felton, 1999). Hence, most of the studies center on reading fluency in the aspect of accuracy mostly (Kuhn, Schwanenflugel \& Meisinger, 2010). Through several comprehensive reviews, reading fluency is later defined in more precise way whereby it refers to the "ability to read text quickly, accurately and with proper expression (NICHD, 2000; Rasinski, 2004; Hudson, Mercer \& Lane, 2000). In other words, reading fluency can be measured in the aspects of accuracy, rate as well as prosody. Nonetheless, there is a lack of researches that investigate thoroughly on the pupils' reading fluency in all three components of accuracy, rate and prosody. This is supported by Rasinski, Rikli and Johnson (2009) who mentioned about limited research especially in prosody component of reading fluency.

Since the publication of the NRP report, there is a considerable change in the field of reading fluency. It is revealed that phonics instruction contributes greatly to the development of pupils' reading fluency (NICHD, 2000). In this context, it refers to the synthetic phonics instruction. It is not surprising that countries such as Australia, United Kingdom, New Zealand and United States have been adopting synthetic phonics in schools with the intention of producing fluent readers in the early stages (Davies \& Ritchie, 2003; Ehri, 2003). Thus, the effectiveness of synthetic phonics on reading fluency is indisputable although most of the researches do not measure reading fluency as a whole. For instance, the research conducted by Gomez (2016) proved synthetic phonics to be effective on the reading fluency of the first-grade pupils in term of rate. Meanwhile, there are also some researches which found synthetic phonics to be effective in accuracy aspect of reading fluency among young learners (Torgerson, Brooks \& Hall, 2006; McArthur et al., 2018; Day, 2017).

As one of the foundational skills, it is undeniable that phonics plays critical role in reading as pupils require the phonetic knowledge to decode the words easily. English is an alphabetic code (Moats, 2000; Christo \& Davis, 2008). In order to crack the code, the learning of phonics is necessary whereby pupils learn to recognise and identify the letter sounds or phonemes that are represented by letters. Accuracy in reading fluency is achieved when pupils can decode words by blending the phonemes in each word correctly. As stated by Hudson, Lane and Pullen (2005), accuracy in reading fluency requires "a strong understanding of the alphabet principle and the ability to blend the sounds together". After accuracy is acquired, rate in reading fluency will be the next goal as acquiring accuracy alone is not sufficient in achieving reading fluency. In this context, rate refers to the speed in reading (Rasinski, 2004). However, it does not mean that fast readers are fluent readers (Callella, 2003; International Literacy Association, 2018) as they might read without accuracy, phrasing or even understanding. Thus, moderate reading rate that sounds natural and automatic is the optimum level. To reach this automaticity level, a strong foundation in phonics is a prerequisite to ensure that pupils can decode words quickly and accurately without spending too much time. This aligns with the theory of automaticity proposed by LaBerge \& Samuels (1974) in which reading becomes effortless and natural. As for prosody, it considers the elements of pitch, tone, volume, intonation, phrasing and pausing in reading (International Literacy Association, 2018). Without these elements, it will result in expressionless, unmeaningful and monotone reading which will directly impede comprehension in reading. In sum, all these components build upon one another and are the key indicators of reading fluency.

\section{Methodology}

This research adopted an action research design as it offered "systematic approach to investigation" which enabled a more comprehensive research to be conducted to gain precise and valid data (Stringer, 2014). The researcher employed Kemmis and McTaggart's model (1988) which consisted of two cycles of planning, acting, observing and reflecting. In this research, a total of six Year 2 intermediate participants who are studying in a sub-urban primary school in Dalat, Sarawak were involved and selected through purposeful sampling. These pupils were chosen intentionally to attend to the research problem.

With reference to the model, firstly, the researcher planned the intervention schedule and administered a pre-test using Oral Reading Fluency assessment adapted by Rasinski (2004) for initial data collection. After that, intervention began whereby participants were exposed to series of activities related to phonological awareness, letter-sound correspondence, blending and segmenting phonemes and sight words with readers. The intervention lasted for 10 weeks with 30 intervention sessions in overall. In each week, the participants attended for 3 sessions in a week which took for an hour each. They were exposed to 5 sets of phonemes (42 phonemes) as outlined in the KSSR (MoE, 2011). Additionally, 3 sets of Dolch sights words (21 sight words) were taught to them as well through fun-filled activities such as "Pat It Right", "Say It Out Quick" and "Sight Words Board Game". After completing 2 sets of phonemes and 1 set of sight words, the researcher began using Sight Word Readers (Set 1) to guide the participants to read with fluency. Each Sight Words Reader consisted of a short story which incorporated the phonemes and sight words learnt in the related session. Similar steps were repeated until all sets of phonemes, sight words and Sight Words Readers (3 sets) were completed. Throughout the intervention, classroom observation took place with the researcher played the role as a participant observer to collect authentic data and "see experiences" from participants' view in better way (Creswell, 2012). Field notes were recorded during the observed for data analysis purpose. Lastly, the researcher reflected and improvised the intervention to be conducted in next cycle. The same procedures were repeated for the $2^{\text {nd }}$ cycle.

Upon the completion of each cycle, a post-test was administered to the participants in one-on-one setting using ORF assessment. With the inclusion of 2 cycles in this research, this added up to two post-tests in overall. During the prepost-tests, participants' reading fluency was measured in the components of accuracy, rate and prosody. Each participant 
was asked to read a graded-level passage for a minute. Accuracy in reading fluency was calculated in the percentage of words read correctly within a minute (WCPM); reading rate was calculated by comparing the total number of correctly read words to the target norm proposed by Hasbrouck and Tindal (2006) while prosodic reading was assessed using a multidimensional fluency rubric developed by Zutell and Rasinski (1991). The same passage was used for both pre-test and post-tests to ensure its reliability. Apart from ORF assessment and classroom observation, structured interviews were conducted as well to collect data related to the participants' perceptions towards the intervention. One-on-one interviews were adopted with only one participant involving in the questioning and answering session at a time which was led by the researcher (Creswell, 2012). The rationale behind this option was to provide a comfortable setting for the participants to "share ideas comfortably" (Creswell, 2012). A total of 7 questions was asked to each participant.

To analyse the data, paired T-tests were conducted by the researcher based on the data gained in the pre-posttests. Paired T-tests were selected as the data analysis method to determine whether there was significant difference in the reading fluency scores of each component before and after the intervention. Mean, standard deviation, $t$-value and $\mathrm{p}$ value were calculated for analysis purposes. As for the classroom observation, the field notes recorded were analysed thematically whereby the researcher coded and categorised the data into themes. Creswell (2012) described coding as "the process of segmenting and labelling text to form descriptions and broad themes in the data". On the other hand, the structured interviews were transcribed verbatim and analysed thematically as well which concerned on the participants' perception on synthetic phonics in developing their reading fluency.

\section{Results and Discussion}

\subsection{Shapiro-Wilk Normality Test}

\begin{tabular}{|c|c|}
\hline Components of Reading Fluency & p-value \\
\hline Accuracy & 0.120 \\
\hline Rate & 0.543 \\
\hline Prosody & 1.178 \\
\hline
\end{tabular}

Table 1: Shapiro-Wilk Normality Test for Post-Test Score in Reading Fluency Components

Before carrying out the paired t-test for this research, a normality test was conducted beforehand to ensure the normal distribution of the data obtained. Since the sample size was less than 50, Shapiro-Wilk normality test was used. As indicated in Table 1 below, the p-value for the post-test score in each reading fluency component exceeded 0.05 (accuracy=0.120; rate $=0.543$; prosody $=1.178$ ). This indicated that the data obtained for this research was normally distributed with $\mathrm{p}>0.05$.

\subsection{Effectiveness of Synthetic Phonics on Reading Fluency}

\subsubsection{Paired T-tests}

With normal distribution of the data gained, paired t-test was then administered to determine whether there was significant difference in reading fluency score for each component before and after the synthetic phonics intervention. The findings were presented and discussed in this section.

\subsubsection{Paired T-Test of Accuracy Component in Reading Fluency}

\begin{tabular}{|c|c|c|c|c|c|c|}
\hline \multirow{2}{*}{$\begin{array}{c}\text { Component in } \\
\text { Reading Fluency }\end{array}$} & \multicolumn{2}{|c|}{ Mean score } & \multirow{2}{*}{$\begin{array}{c}\text { Mean } \\
\text { Difference }\end{array}$} & \multirow{2}{*}{$\begin{array}{l}\text { Standard } \\
\text { deviation }\end{array}$} & \multirow[t]{2}{*}{ t-value } & \multirow[t]{2}{*}{ p-value } \\
\hline & Pre test & Post test & & & & \\
\hline Accuracy & 55.23 & 87.13 & 31.90 & 11.45 & 6.827 & 0.001 \\
\hline
\end{tabular}

Table 2: Paired T-Test of Accuracy in Reading Fluency before and After the Intervention

Based on the findings in Table 2, it showed that there was a difference in the mean score gained between the pretest and post-test for accuracy component in reading fluency. The t-value and p-value obtained in this T-test were 6.827 and 0.001 respectively. With the $p$-value of smaller than $0.05(\mathrm{p}=0.001)$, it was deduced that there was a significant difference in accuracy score gained in the ORF assessment before and after the synthetic phonics intervention. This is in line with the past studies conducted by other researchers that had proven synthetic phonics to be indeed effective in developing the accuracy aspect of reading fluency (Torgerson, Brooks \& Hall, 2006; McArthur et al., 2018; Day, 2017). In this research, reading accuracy was measured in term of percentage of words read correctly within one minute of passage reading. As stated by Rasinski (2004), an accuracy scores below 90\% signifies that pupils are yet to achieve accuracy in reading. Albeit the average accuracy score of $87.13 \%$ in the post-test was yet to meet the target, there was a considerable improvement of the participants within 5 weeks. The letter-sound correspondence embedded in phonics learning is fundamental for word decoding process due to the alphabetic nature of English language. With 26 letters which can make up to 44 phonemes or sounds, English words relies heavily on the acquisition of letter-sound correspondence to be able to translate the letters into spoken words. A lack of understanding of the relationship between letters and sounds will not lead to actual reading. Instead, reading will merely be treated as rote learning process which is equivalent to the sight 
word approach adopted by teachers in previous days. As reported by a first-grade reading teacher (as cited in Wolf, 1998), "Children can learn to read many words by sight. But if somewhere along the way they do not learn to decode, they will not learn to read". This showed the crucial role of phonics as the underlying foundation in learning to read.

\subsubsection{Paired T-Test of Rate Component in Reading Fluency}

\begin{tabular}{|c|c|c|c|c|c|c|}
\hline $\begin{array}{c}\text { Component in } \\
\text { Reading Fluency }\end{array}$ & \multicolumn{2}{|c|}{$\begin{array}{c}\text { Mean Score } \\
\text { (Word Correct Per Minute) }\end{array}$} & $\begin{array}{c}\text { Mean } \\
\text { Difference }\end{array}$ & $\begin{array}{c}\text { Standard } \\
\text { deviation }\end{array}$ & t-value & p-value \\
\cline { 2 - 6 } & Pre test & Post test & & 21 & 5.884 & 0.002 \\
\hline Rate & 14 & 64 & 50 & \multicolumn{2}{|c|}{ Table 3: Paired T-Test of Rate in Reading Fluency before and after the Intervention } \\
\hline
\end{tabular}

As for the component of rate in reading fluency, the t-value and p-value obtained were 5.884 and 0.002 respectively as shown in Table 3 . With the p-value of $0.002(\mathrm{p}<0.05)$, it was concluded that there was a significant difference in the rate score gained in the ORF assessment before and after the synthetic phonics intervention. In this context, the reading rate of participants was measured in the number of words correctly read within a minute (WCPM) based on the passage provided. The participants were found to increase in their reading rate during the post test. This was related to their strong foundation in phonics. As indicated in Table 2, synthetic phonics had helped the participants to read words accurately. With the acquisition of accuracy followed by consistent reading practice using the Phonics Readers as well as learning of sight words in the intervention, the participants were noticed to spend less time in blending and sounding out the words. Their increased automaticity in reading during the post-test was the best evidence as presented in Table 3 above. This confirms LaBerge and Samuels' (1974) theory of automaticity that when a low level reading subskill reaches the level of automaticity, a reader's mind will be freed to pave way for other skills in reading. Although the average score gained in the post-test did not meet the target score of 72 words correctly read in a minute as stated in Hasbrouck \& Tindal's ORF norm (2006) the participants were making great progress in comparison of their performance before the intervention with an average of 14 words correctly read in a minute as presented in Table 3 . Hence, phonics and automaticity in reading are interrelated which directly determine a reader's success in reading (Adams, 1990; LaBerge \& Samuels, 1974; Ehri, 2005; Kuhn, Schwanenflugal \& Meisinger, 2010).

\subsubsection{Paired T-Test of Prosody Component in Reading Fluency}

\begin{tabular}{|c|c|c|c|c|c|c|}
\hline \multirow{2}{*}{$\begin{array}{c}\text { Component in } \\
\text { Reading } \\
\text { Fluency }\end{array}$} & \multicolumn{2}{|c|}{ Mean score } & \multirow[b]{2}{*}{$\begin{array}{c}\text { Mean } \\
\text { Difference }\end{array}$} & \multirow[b]{2}{*}{$\begin{array}{l}\text { Standard } \\
\text { deviation }\end{array}$} & \multirow[b]{2}{*}{ t-value } & \multirow[b]{2}{*}{ p-value } \\
\hline & Pre test & Post test & & & & \\
\hline Prosody & 5.83 & 11.50 & 5.67 & 2.16 & 6.425 & 0.001 \\
\hline
\end{tabular}

Table 4: Paired T-Test of Prosody in Reading Fluency before and after the Intervention

Apart from accuracy and rate, synthetic phonics intervention was also found to be effective in developing the prosody component of reading fluency in this research. As we could see from Table 4, the t-value and p-value gained in paired T-test of prosody component were 6.425 and 0.001 respectively. The $p$-value of $0.001(p<0.05)$ signified that there was a significant difference in the prosody score gained in the ORF assessment before and after the synthetic phonics intervention. To measure the participants' prosody in reading, they were required to read a graded-level passage and be evaluated using Zutell and Rasinski's (1991) multidimensional fluency rubric. The rubric incorporates the prosodic elements of expression and volume, phrasing, smoothness and pace. Prosody score of 10 and above signifies that an individual is making good progress in his or her prosodic reading. The average prosody score of 11.50 as depicted in Table 4 had met the criteria of a fluent reader. Though there was limited research related to influence of synthetic phonics instruction on prosody in reading fluency (Rasinski, Rikli \& Johnson, 2009), it is believed that it had certain impact on prosody as identified in this research. This is because pupils do not merely learn about phonetic knowledge during synthetic phonics instruction, but also learn to read a text fluently through repeated reading. In this research, the Phonics Readers were used as the reading materials throughout the intervention but other graded-level reading material was used in the post-test to produce a trustworthy research. The link between reading rate and prosody was also emphasised by Rasinski (2012) who claimed that both components should "go hand in hand" as they were developed in similar manner which was through repeated reading. The skills learnt from the previous repeated reading could also be transferred and applied in new reading (Rasinski, 2012) on condition that phonetic knowledge was mastered beforehand. Otherwise, the aims to achieve accuracy, rate and prosody in reading fluency would not be fulfilled. 


\subsubsection{Classroom Observation}

\begin{tabular}{|c|c|}
\hline \multicolumn{2}{|c|}{ Participants' Actions and Responses } \\
\hline First Cycle & Second Cycle \\
\hline $\begin{array}{l}\text { a) Reading accuracy: } \\
\text {-Participants could decode words accurately } \\
\text { although they might take some time. } \\
\text {-Some mispronunciations in reading. }\end{array}$ & $\begin{array}{l}\text { a) Reading accuracy: } \\
\text {-Participants could apply blending skill to decode } \\
\text { words with ease. } \\
\text {-Less reading mistakes detected. } \\
\text { - Self-correction was noticed among participants. }\end{array}$ \\
\hline $\begin{array}{l}\text { b) Reading rate: } \\
\text {-Their reading sounded a bit smoother. } \\
\text {-Some pauses in reading. } \\
\text {-Increase in reading rate }\end{array}$ & $\begin{array}{l}\text { b) Reading rate: } \\
\text {-They read in moderate rate, neither too fast nor too } \\
\text { slow. } \\
-2 \text { participants exceeded the target of } 72 \text { correctly } \\
\text { read words in a minute. (Ray-75 words; Rina- } 77 \\
\text { words) }\end{array}$ \\
\hline $\begin{array}{l}\text { (c) Prosodic reading: } \\
\text {-Reading sounded natural in part of the text with } \\
\text { occasional breaks. } \\
\text {-They read with volume and expression but } \\
\text { sometimes slipped into expression reading. } \\
\text {-They read with phrasing in rhythm. }\end{array}$ & $\begin{array}{l}\text { (c) Prosodic reading: } \\
\text {-Occasional breaks in reading. } \\
\text {-They read with stress and intonation. } \\
\text {-Self-correction was noticed. } \\
\text {-A participant could read quite smoothly and fluently } \\
\text { as if she was speaking. (Ash) }\end{array}$ \\
\hline
\end{tabular}

Table 5: An Excerpt of Field Notes during the Classroom Observation

Table 5 portrayed an excerpt of field notes recorded by the researcher during the intervention. Participants were observed to be more confident in reading after 2 cycles of intervention. They were able to decode words more accurately in second cycle with lesser reading errors detected in their reading within one minute. Moreover, they were noticed to self-correct themselves when they found themselves read inaccurately. In the aspect of their reading rate, the researcher observed that they were able to read in a moderate rate in second cycle which was neither too fast nor too slow. This was a good sign because fast readers might not be fluent readers because they often overlooked the accuracy and phrasing in reading (Callella, 2003).

Most importantly, there were 2 participants, namely Ray and Rina who managed to surpass the target rate of reading at least 72 words accurately in a minute as stated in the ORF target rate norm (Hasbrouck \& Tindal, 2006). This further proved that synthetic phonics was indeed impactful in developing reading accuracy of the participants which later promoted their speed in reading as automaticity was achieved. As mentioned by Kuhn, Schwanenflugal \& Meisinger (2010), in order to read fluently, one of the tasks is required to be automatic so that there is cognitive energy left for other tasks.

In term of prosodic reading, it is noted that the participants had not achieved the natural level in which reading did not sound like they were talking to a friend. Occasional breaks were detected in the 1-minute reading. Nonetheless, the researcher noticed that they read with appropriate phrase, volume and expression most of the time. Monotone reading was seldom being heard in the participants' reading. Thus, it is believed that their performance could be improved with consistent practice in reading. This corresponds with Rasinski's (2012) claim that readers could slowly recognise and apply prosodic elements by reading of a wide variety of texts.

\subsection{Pupils' Perception towards Synthetic Phonics on Reading Fluency}

\subsubsection{Structured Interview}

Interview Transcript

T: Why do you not feeling difficult to read the book?

S: Because it can be combined.

$\mathrm{T}$ : ... You mean combine the phonemes?

S: Em.

$\mathrm{T}$ : Do you like to read using the phonics approach with the blending method?

S: I like it.

T: Why?

S: Because it is easy to read.

Figure 1: One-On-One Interview with Sam

${ }^{*} T$ - Teacher (Researcher)

${ }^{*} S$ - Sam (Participant) 


\section{Interview Transcript}

T: Do you feel more confident to read a passage now?

A: Yes.

T: Do you still want to join this reading programme?

A: Yes.

T: Why do you want to join again?

A: Because it is easy to spell.

Figure 2: One-On-One Interview with Ash

${ }^{*} T$ - Teacher (Researcher)

${ }^{*}$ A- Ash (Participant)

Through the one-on-one interviews with the participants, it was identified that synthetic phonics intervention had yielded positive perception among them. As shown in Figure 1, one of the participants, Sam expressed that he did not feel difficult to read the readers as phonics had helped him to blend phonemes and sound them into words. In fact, he liked to use phonics approach in learning to read as reading had become an easy task with this approach. Meanwhile, Ash stated that she had gained more confidence in reading a passage after the intervention. She also expressed her desire to continue attending the intervention in the future because "it is easy to spell" as revealed in Figure 2. In other words, she felt that learning of phonics had helped her to decode words through blending the sounds of each letter. As mentioned by Wolf (2018), phonics focuses on "letters and spelling patterns" to promote automatic word decoding. On top of that, the success of this intervention was further affirmed when Ray and Almar also expressed their willingness to attend the intervention again. As indicated in Figure 3, Ray commented that the intervention was good because he got to learn to read eventually. As for Almar, he thought that the intervention was fun which could be seen in Figure 4. Hence, fun-filled learning was necessary which aligned with Prasad, Nooreiny and Hamidah's (2016) research findings that pupils enjoy phonics lessons due to the fun and meaningful activities.

\section{Interview Transcript}

T: You want to join it again. Why?

R: Because ... it is good.

T: Because it is good? You get to learn to read, is it?

R: All.

Figure 3: One-On-One Interview with Ray

*T- Teacher (Researcher)

${ }^{*} R$ - Ray (Participant)

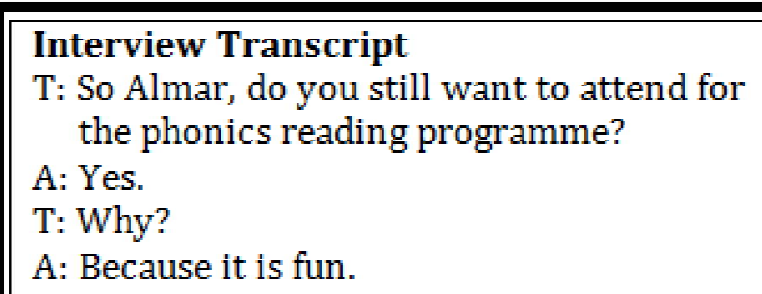

Figure 4: One-On-One Interview With Almar

*T- Teacher (Researcher)

${ }^{*} A$ - Almar (Participant)

\section{Conclusion}

It is undeniable that the reading fluency is gaining more concern nowadays in the field of reading due to the growing number of pupils who are struggling to read fluently including Grade 5 pupils (Rasinski et al., 2005; Morris \& Gaffney, 2011) and pupils in high schools (Rasinski et al., 2005). This is in fact a worrying situation because a lack in reading fluency will directly impede the reading comprehension among the pupils (LaBerge \& Samuels, 1974; Adams, 1990; Philips \& Torgensen, 2006; Rasinski \& Hoffman, 2006; Kuhn, Schwanenflugal \& Meisinger, 2010). The close relation between fluency and comprehension should not be underestimated for the sake of pupils' reading success in future. The learning of phonics had played a major role as highlighted in this research. The findings of this research managed to provide some insights on how a systematic phonics instruction was effective in contributing the development of reading fluency among the struggling readers. There has been a misconception that pupils who can decode words accurately will 
be able to understand what is being read. Having accuracy alone is insufficient in making an individual a good, fluent reader. For example, a reader who reads accurately and quickly but without phrasing is not considered a fluent reader because the reading sounds meaningless (Rasinski, 2012). Many researchers also contended that fluency in reading is demonstrated through accuracy, rate and prosody (Adams, 1990; Dahl, 1974; Kuhn \& Stahl, 2003; Rasinski, 2004; Chard, Vaughn \& Tyler, 2002; Fuchs et al., 2001). Hence, all the components of reading fluency should be considered to truly master fluency in reading.

With the positive outcome gained in this research, it also sheds some light on how ORF assessment can be adopted in the classroom to assess and monitor the reading fluency progress of the pupils. Although reading fluency is not part of the learning reading goal in the recent curriculum, it is recommended that our Ministry of Education is more aware of the dire need to put emphasis on the component of reading fluency alongside with other existing components in the English language curriculum. As far as we are concerned, reading fluency is not being listed as one of the components to be assessed in any formal tests or even in the current Classroom Based Assessment. The major concern is on reading comprehension since it is the ultimate goal in reading. Thus, it is hoped that more researches can be done in this area which involve greater sample size and various schools in different settings (urban, sub-urban and rural areas) to generalise and strengthening the findings. Besides that, future researches can also attend to pupils of all proficiency levels to examine on the effectiveness of synthetic phonics in the development of reading fluency. In fact, teachers can actually relate the phonics learning which has been part of the embedded reading goal in our curriculum with reading fluency in the classroom. The ORF assessment used in this research is easy to administer which only takes a minute for a pupil. Moreover, this assessment is valid and reliable as it examines the reading fluency of the pupils comprehensively in the aspects of accuracy, rate and prosody (Rasinski, 2004). Multiple assessments are highly recommended as well so that teachers, parents and pupils are well-informed of the current performance in reading fluency for further actions (Deno, 1997; Rasinski, 2004).

In order to avoid any reading difficulties which will hinder the pupils' success in future, it is vital for reading instruction to take place as soon as possible. As reported in NRP report (NICHD, 2000), first grade is the "keystone grade" to develop early reading skills among the young learners. Reading has never been an easy task even for the intermediate pupils in this research. It is a cumulative task which "snowballs from the early grades on" (Rasinski, 2004; Duke, Pressley \& Hilden, 2004; Paris \& McNaughton, 2010). This is in line with the Matthew Effect proposed by Stanovich (1986) whereby readers who have gained fluency in early years will be motivated to read more, resulting in a higher level of reading fluency. Conversely, readers who fail to acquire fluency in early years will continue to fall behind their peers due to their lack in fluency. Therefore, it is vital for teachers to build a strong foundation of phonics skill among the pupils in preschool, Year 1 and 2 in adherence to our English syllabus (MoE, 2018). Enforcement of phonics learning is very much needed in early years and ought to be taken seriously before the pupils proceed to learn more complex skills in reading.

To conclude, acquiring phonics solely is not sufficient in developing fluent readers but it is the main key which forms the foundation in becoming a fluent reader. Without the learning of synthetic phonics, it will be difficult to achieve fluency in reading because the most basic skill in decoding words is not acquired yet. Hence, the significant role of synthetic phonics should not be underestimated as it leads to reading fluency. Most important of all, early intervention can also be provided to the pupils with reading fluency problem immediately before they are left behind from their peers. With the findings obtained in this research, it is hoped that more researches can be carried out to validate the effectiveness of synthetic phonics in the field of reading fluency.

\section{References}

i. Adams, M. J. (1990). Beginning to read: Thinking and learning about print. Cambridge, MA: MIT Press.

ii. Allington, R. L. (1983). Fluency: The neglected reading goal in reading instruction. The Reading Teacher, 36(1), 556-561.

iii. Callella, T. (2003). Developing reading fluency, Grade 3: Using modelled reading, phrasing and repeated oral reading. Cypress, CA: Creative Teaching Press.

iv. Chall, J. (1967). The great debate. New York: McGraw Hill.

v. Chall, J. S., Jacobs, V. A. \& Baldwin, L. E. (1990). The reading crisis: Why poor children fall behind. Cambridge, MA: Harvard University Press.

vi. Chard, D. J., Vaughn, S. \& Tyler, B. J. (2002). A synthesis of research on effective interventions for building reading fluency with elementary students with learning disabilities. Journal of Learning Disabilities, 35(1), 386-406.

vii. Christo, C. \& Davis, J. (2008). Rapid naming and phonological processing as predictors of reading and spelling. The California Association of School Psychologists, 13, 7-18.

viii. Creswell, J. W. (2012). Educational research: Planning, conducting and evaluating quantitative and qualitative research. USA: Pearson Education.

ix. Dahl, P. (1974). An experimental program for teaching high speed word recognition and comprehension skills. Bloomington, MN: Bloomington Public Schools.

x. Davies, A. \& Ritchie, D. (2003). Teaching THRASS whole picture keyword phonics: The essential guide to progression and assessment for all teachers of English. WA: THRASS.

xi. Day, B. B. (2017). Exploring the relationship between the use of a selected phonics curriculum and the oral reading fluency and nonsense word fluency scores of first-grade students (Doctoral dissertation). Retrieved from All Graduate Theses and Dissertations. (6864).

xii. $\quad$ Deno, S. L. (1997). "Whether" thou goest: Perspectives on progress monitoring. In E. Kameenui, J. Lloyd \& D. Chard (Eds), Issues in educating students with disabilities (pp. 77-99). Mahwah, NJ: Erlbaum. 
xiii. Denton, C. A. \& Otaiba, S. A. 2011. Teaching word identification to students with reading difficulties and disabilities. Focus on Exceptional Children, 43(7), 1-16.

xiv. Ding, J. Y. (2015). A case study on the use of phonics instruction, implicit and explicit, to help low proficiency ESL learners at primary level to develop proficiency and enjoyment in English reading. (Master's thesis). Retrieved from http://libdr1.ied.edu.hk/pubdata/img00/arch00/link/archive/1/instarh/4408.pdf

xv. Dudley, A. M. \& Mather, N. (2005). Getting up to speed on reading fluency. New England Reading Association Journal, 41(1), 22-27.

xvi. Duke, N. K., Pressley, M., \& Hilden, K. (2004). Difficulties in reading comprehension. In C.A Stone, E.R. Silliman, B.J. Ehren, \& K. Apel (Eds.), Handbook of Language and Literacy: Development and Disorders (pp. 501-520). New York: Guilford.

xvii. Ehri, L. (2003). Systematic Phonics Instruction Findings of the National Reading Panel. Paper presented at the Paper presented at the invitational seminar organized by the Standards and Effectiveness Unit DES British Government, London, Britain.

xviii. Ehri, L. C. (2005). Learning to read words: Theory, findings, and issues. Scientific Studies of Reading, 9(2), 167-188.

xix. Ehri, L. C., Nunes, S. R., Stahl, S. A. \& Willows, D. M. (2001). Systematic phonics instruction helps students learn to read: Evidence from the National Reading Panel's meta-analysis. Review of Educational Research, 71(3), 393-447. https://doi.org/10.3102/00346543071003393

xx. Fuchs, L. S., Fuchs, D., Hosp, M. D. \& Jenkins, J. (2001). Oral reading fluency as an indicator of reading competence: A theoretical, empirical, and historical analysis. Scientific Studies of Reading, 5(3), 239-256. https://doi.org/10.1207/s1532799xssr0503_3

xxi. Gomez, D. E. (2016). The impact of explicit phonics instruction on the fluency rate of first graders (Master's thesis). Retrieved from https://pdfs.semanticscholar.org/24c2/aa65eabf0fd8ac8fc0326313f63c861949f1.pdf

xxii. Guerin, A. \& Murphy, B. (2015). Repeated reading as a method to improve reading fluency for struggling adolescent readers. Journal of Adolescent \& Adult Literacy, 58(7), 551-560. https://doi.org/10.1002/jaal.395

xxiii. Hasbrouck, J. \& Tindal, G. A. (2006). Oral reading fluency norms: A valuable assessment tool for reading teachers. The Reading Teacher, 59(7), 636-644.

xxiv. Hasbrouck, J. E. \& Tindal, G. (1992). Curriculum-based oral reading fluency norms for students in Grades 2-5. Teaching Exceptional Children, 24(3), 41-44.

xxv. Hosp, M. K., Hosp, J. L. \& Howell, K. W. (2007). The ABC's of CBM: A practical guide to curriculum-based measurement. New York: Guilford Press.

xxvi. Hudson, R. F., Lane, H. B. \& Pullen, P. C. (2005). Reading fluency assessment and instruction: What, why and how? The Reading Teacher, 58(8), 702-714.

xxvii. Hudson, R. F., Mercer, C. D. \& Lane, H. B. (2000). Exploring reading fluency: A paradigmatic overview. Unpublished manuscript, University of Florida, Gainesville.

xxviii. International Literacy Association. (2018). Reading fluently does not mean reading fast: Literacy leadership brief. Newark, DE: Author.

xxix. Jolliffe, W. \& Waugh, D. (2017). NQT: The beginning teacher's guide to outstanding practice. London: SAGE Publications.

xxx. Kemmis, S. \& McTaggart, R. (1988). The action research reader. Victoria: Deakin University Press.

xxxi. Khairul Azhar Jamaludin, Norlidah Alias \& Roselina Johari. (2014). Research and trends in the studies of phonological knowledge and reading development: A review on selected journals. The Malaysian Online Journal of Educational Science 2(2), 27-36.

xxxii. Kim, Y. H. \& Goetz, E. T. (1995). Children's use of orthographic and contextual information in word recognition and comprehension. Dordrecht: Springer.

xxxiii. Kuhn, M. R. \& Stahl, S. A. (2003). Fluency: A review of developmental and remedial practices. Journal of Educational Psychology, 95(1), 3-21.

xxxiv. Kuhn, M. R., Schwanenflugal, P. J. \& Meisinger, E. B. (2010). Aligning theory and assessment of reading fluency: Automaticity, prosody and definitions of fluency. Reading Research Quarterly, 45(1), 230-251.

xxxv. LaBerge, D. \& Samuels, S. J. (1974). Towards a theory of automatic information processing in reading. Cognitive Psychology, 6(1), 293-323.

xxxvi. Lehner, E. (2017). Probing the enactment of reading miscues: A study examining reading fluency. International Journal of English Linguistics, 7(1), 14-24.

xxxvii. Mc Candliss, B., Beck, I. L., Sandak, R., \& Perfetti, C. (2003). Focusing attention on decoding for children with poor reading skills: Design and preliminary tests of the word building intervention. Scientific Studies of Reading, 7(1), 75-104.

xxxviii. McArthur, G., Eve, P.M., Jones, K., Banales, K., Kohnen, S., Anandakumar, T., Larsen, L., Marinus, E., Wang, H. C. \& Castles, A. (2018). Phonic training for English-speaking poor readers. Cochrane Database of Systematic Reviews. https://doi.org/10.1002/14651858.CD009115.pub3

xxxix. Meyer, M. S. \& Felton, R. H. (1999). Repeated reading to enhance fluency: Old approaches and new direction. Annuals of Dyslexia, 49(1), 283-306.

xl. Ministry of Education. (2018). KSSR English Language Scheme of Work for Phonics Primary Year 1. Putrajaya: Bangunan Pembangunan Kurikulum.

xli. Moats, L. C. (2000). Speech to print: Language essentials for teachers. Baltimore: Paul H. Brookes. 
xlii. Morris, D., \& Gaffney, M. (2011). Building reading fluency in a learning-disabled middle school reader. Journal of Adolescent \& Adult Literacy, 54(5), 331-341.

xliii. National Institute of Child Health and Human Development. (2000). Report of the National Reading Panel: Teaching children to read. Washington, DC: NICDH.

xliv. National Reading Panel (2000). Teaching children to read: An evidence-based assessment of the scientific research literature on reading and its implications for reading instruction. National Institute of Health Publication No. 00-4769. https://doi.org/10.1002/ppul.1950070418

xlv. Organisation for Economic Cooperation and Development (2019). PISA 2018 Results: Combined Executive Summaries Volume I, II \& III. Paris: OECD Publishing.

xlvi. Paris, S. \& McNaughton, S. (2010). Social and cultural influences on children's motivation for reading. In D. Wyse, R. Andrews \& J. Hoffman (Eds), The international handbook of English, language and literacy teaching (pp. 11-21). London, UK: Routledge.

xlvii. Phillips, B. M. \& Torgesen, J. K. (2006). Phonemic awareness and reading: Beyond the growth of initial reading accuracy. Handbook of Early Literacy Research, 2, 101-112.

xlviii. Pokharel, P. K. (2018). Learning to read and reading to learn in English. Journal of NELTA Surkhet, 5, 75-81.

xlix. Prasad, R. D., Nooreiny Maarof \& Hamidah Yamat. (2016). Implementing phonics in Malaysia. International Journal of English Language Teaching and Linguistics, 1(1), 1-17.

l. Rasinski, T. \& Nageldinger, J. K. (2016). The fluency factor: Authentic instruction and assessment for reading success in the common core classroom. NY: Teachers College Press.

li. Rasinski, T. (2016). Is what's hot in reading what should be important for reading instruction? Literacy Research and Instruction, 55(1), 134-137.

lii. Rasinski, T. V. (2003). The fluent reader: Oral reading strategies for building word recognition, fluency and comprehension. New York: Scholastic.

liii. Rasinski, T. V. (2012). Why reading fluency should be hot! The Reading Teacher, 65(8), 516-522.

liv. Rasinski, T., \& Hoffman, J. (2006). Seeking understanding about reading fluency: The contributions of Steven A. Stahl. K. S. D. Stahl \& M. C. McKenna (Eds.). New York, NY: Guilford.

lv. Rasinski, T., Rikli, A. \& Johnson, S. (2009). Reading fluency: More than automaticity? More than a concern for the primary grades? Literacy Research and Instruction, 48(4), 350-361.

lvi. Rasinski, T.V. (2004). Assessing reading fluency. Honolulu, Hawai'i: Pacific Resources for Education and Learning.

lvii. Rasinski, T.V., Padak, N.D., McKeon, C.A., Wilfong, L.G., Friedauer, J.A., \& Heim, P. (2005). Is reading fluency a key for successful high school reading? Journal of Adolescent \& Adult Literacy, 49(1), 22-27.

lviii. Renukadevi, D. (2013), Communicative English: Why it is essential to emerging engineers; The challenges and remedies. International Journal of Education and Information Studies, 3(2), 51-53.

lix. Shearer, B. A.; Carr, D. A. \& Vogt, M. (2019). Reading specialists and literacy coaches in the real world. USA: Waveland Press.

lx. Stahl, S. A. (2001). Teaching phonics and phonological awareness. Handbook of Early Literacy Research, 1, 333347.

lxi. Stanovich, K. E. (1986). Matthew effects in reading: Some consequences of individual differences in the acquisition of literacy. Reading Research Quarterly, 21(1), 360-407.

lxii. Stockyard, J. \& Engelmann, K. (2010). The development of early academic success: The impact of direct instruction's reading mastery. Journal of Behaviour Assessment and Intervention in Children, 1(1), 2-24.

lxiii. Stringer, E. T. (2014). Action Research. $4^{\text {th }}$ ed. Thousand Oaks, CA: Sage.

lxiv. Tallal, P. (2012). Improving neural response to sound improves reading. Proceedings of the National Academy of Sciences of the United States of America, 109(41), 16406-16407.

lxv. Tankersley, K. (2005). Literacy strategies for Grades 4-12: Reinforcing the threads of reading. Alexandria, VA: Association for Supervision and Curriculum Development.

lxvi. Torgerson, C., Brooks, G. \& Hall, J. (2006). A systematic view of the research literature on the use of phonics in the teaching of reading and spelling. Nottingham: DfES Publications.

lxvii. Wagner, R. K. \& Torgesen, J.K. (1987). The nature of phonological processing and its causal role in the acquisition of reading skills. Psychological Bulletin, 101(2), 192-212.

lxviii. Wolf, G. M. (1998). The three-ingredient reading program: You can teach your child to read. Mesa, AZ: Blue Bird Publishing.

lxix. Wolf, G. M. (2018). Developing Reading Automaticity and Fluency: Revisiting What Reading Teachers Know, Putting Confirmed Re-search into Current Practice. Creative Education, 9(6), 838-855.

lxx. Wolf, M. \& Katzir-Cohen, T. (2001). Reading fluency and its intervention. Scientific Studies of Reading, 5(3), 211239.

lxxi. Wolf, M., Miller, L., \& Donnelly, K. (2000). RAVE-0: A comprehensive fluency-based reading intervention program. Journal of Learning Disabilities, 33(4), 375-386.

lxxii. Wyse, D. \& Goswami, U. (2008). Synthetic phonics and the teaching of reading. British Educational Research Journal, 34(1), 691-710.

lxxiii. Zutell, J. \& Rasinski, T. V. (1991). Training teachers to attend to their students' oral reading fluency. Theory into Practice, 30(3), 211-217. 